\title{
The Mode of Action of Polyene Antibiotics; Induced Potassium Leakage in Candida albicans
}

\author{
By S. M. HAMMOND, P. A. LAMBERT AND B. N. KLIGER \\ Division of Environmental Biology, School of Biological Sciences, \\ Thames Polytechnic, London SEI 86 PF
}

(Received 20 June 1973; revised 22 August 1973)

SUMMARY

With a liquid membrane potassium-sensitive electrode it was shown that lethal concentrations of the polyene antibiotics amphotericin B, candicidin and nystatin caused leakage of $90 \%$ of non-bound potassium ions from Candida albicans. Accurate and rapid determinations of rates of potassium leakage were made directly in suspensions of Candida. Leakage patterns for the three polyenes were very similar, suggesting a common site of action. Differences were noted in the rates of potassium efflux with organisms from cultures of differing ages.

\section{INTRODUCTION}

Amphotericin B, candicidin and nystatin are polyene antibiotics important in the treatment of human mycotic infections, particularly vaginitis caused by Candida albicans. The binding of polyenes by membrane sterols has been known for some time and is well documented (Lampen, I966).

This paper considers the effect of the binding of polyene antibiotics to the membrane on membrane permeability and specifically the selective permeability towards potassium.

\section{METHODS}

Organism and method of culture. Candida albicans NCTC7I3 was grown on Sabouraud dextrose agar slopes at $37{ }^{\circ} \mathrm{C}$ for $24 \mathrm{~h}$ and maintained at $4{ }^{\circ} \mathrm{C}$. From these slopes approximately $10^{6}$ organisms were inoculated into $10 \mathrm{ml}$ Sabouraud dextrose broth (S.D.B.) and incubated with shaking for $\mathrm{I} 8 \mathrm{~h}$ at $37^{\circ} \mathrm{C}$. After centrifuging and washing three times in double distilled water standardized suspensions were made (using a Cecil 303 spectrophotometer $E_{660 \mathrm{~mm}}^{1.2 \mathrm{~cm}}=\mathrm{I} \cdot 0$, equivalent to $23.7 \times 10^{6}$ organisms $/ \mathrm{ml}$ or $0.92 \mathrm{mg}$ dry wt $\left./ \mathrm{ml}\right)$.

Polyene antibiotics. Candicidin, mol. wt $\mathrm{I} 173$ (No. 68I NOF2) of potency $218 \%$ (manufacturer's bioassay, where original candicidin made by S. B. Penick Ltd was given an activity of $100 \%$ ) was supplied by Pharmax Ltd, Bexley, Kent. Amphotericin B,'mol. wt 959 (No. 2B 903) and nystatin, mol. wt 927 (4740 units/mg) were supplied by E. R. Squibb Ltd, Twickenham, Surrey. They were dissolved in dimethyl sulphoxide (DMSO) and then diluted with water or buffer to give a final DMSO concentration of I \%. Fresh solutions were prepared daily. The potency of these antibiotics as measured by microbiological assay (Simpson, 1963) did not change during the experimental period. Aqueous solutions of the antibiotics were protected from light, to which they are sensitive, wherever practicable.

Detection of potassium loss. Leakage of potassium ions was detected with a Phillips $560 \mathrm{~K}$ 


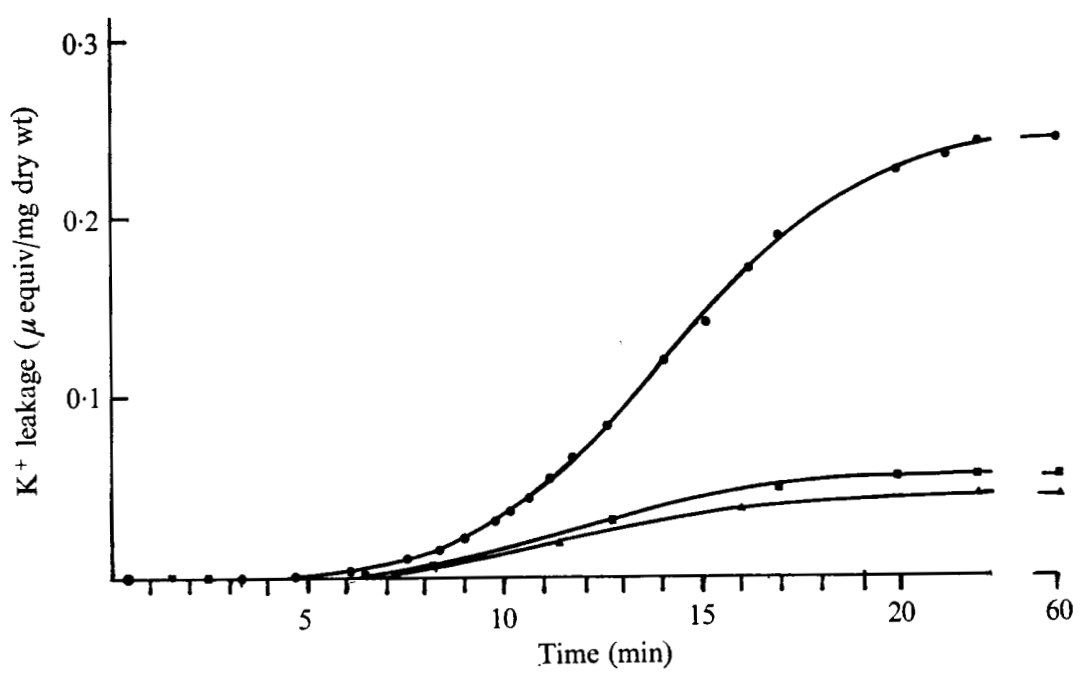

Fig. I. Potassium leakage from the standardized C. albicans suspension (stationary phase) ( $\boldsymbol{\sigma}$ ), and caused by $\mathrm{I} 0 \mu \mathrm{g}$ candicidin/ml (0) and $\mathrm{r} \% \operatorname{DMSO}(\boldsymbol{\Lambda})$.

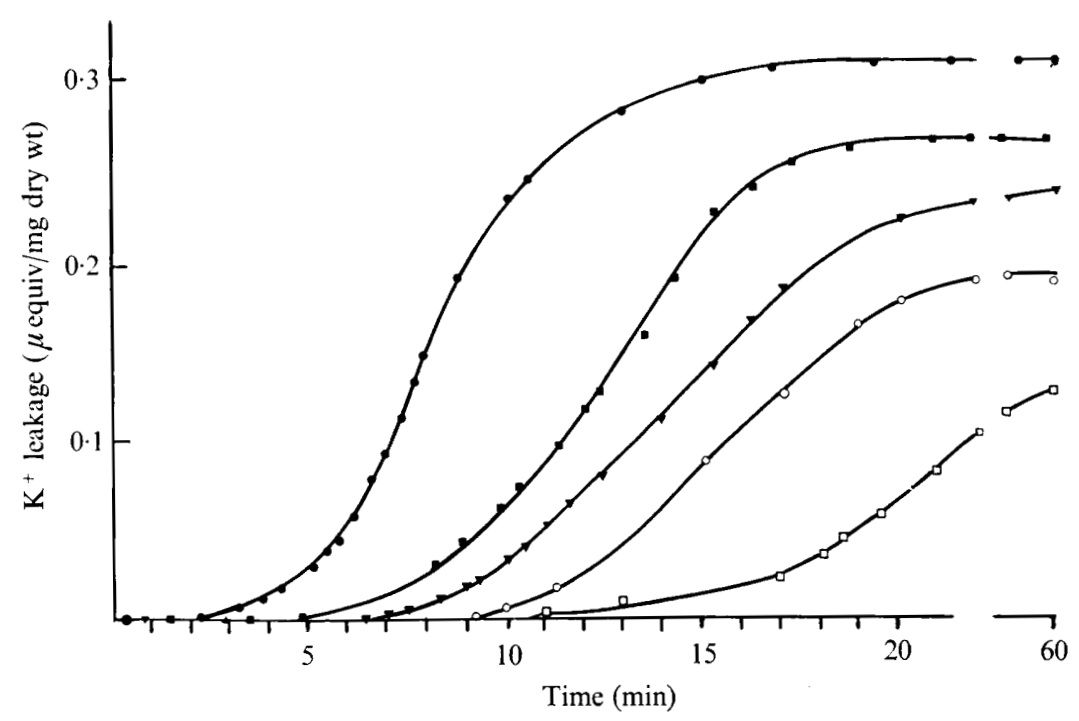

Fig. 2. Potassium leakage induced in C. albicans (stationary phase) by concentrations of candicidin of: $40 \mu \mathrm{g} / \mathrm{ml}(\bullet), 20 \mu \mathrm{g} / \mathrm{ml}(\nabla), 10 \mu \mathrm{g} / \mathrm{ml}(\nabla), 5 \mu \mathrm{g} / \mathrm{ml}(\bigcirc)$, and I $\mu \mathrm{g} / \mathrm{ml}(\square)$.

electrode (Pye Unicam, Cambridge) using a porous polyvinyl chloride membrane containing valinomycin dissolved in diphenyl ether as the ion exchange liquid together with a ground glass sleeve and double junction reference electrode (Phillips R44-2-SD/r). The potential derived from the potassium-sensitive electrode was recorded on a Vibret $46 \mathrm{~A} \mathrm{mV} / \mathrm{pH}$ meter (E.I.L. Ltd, Chertsey, Surrey). Each membrane was calibrated, after preparation, against standardized solutions of $\mathrm{KCl}$. Membranes had a life of approximately $\mathrm{I} 4$ days. The performance of the electrode was also checked against an E.I.L. flame photometer and found to be satisfactory. 


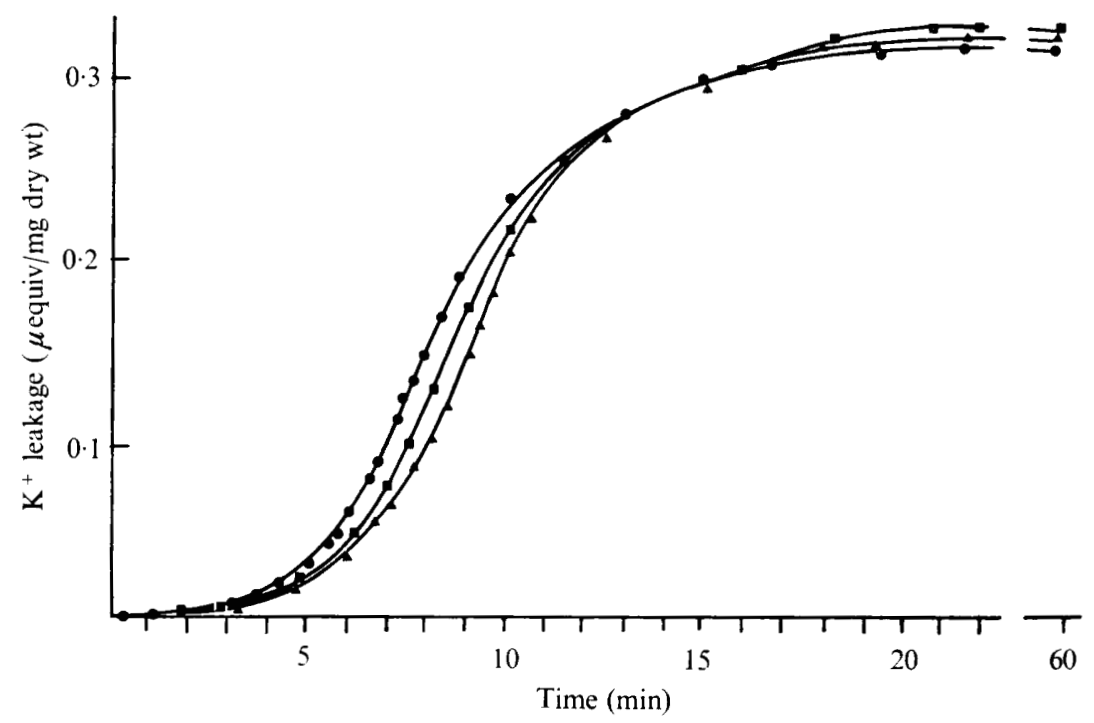

Fig. 3. Potassium leakage from $C$. albicans suspension (stationary phase) caused by $16 \mu \mathrm{M}-$ nystatin

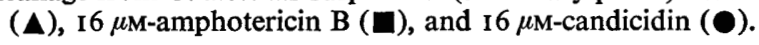

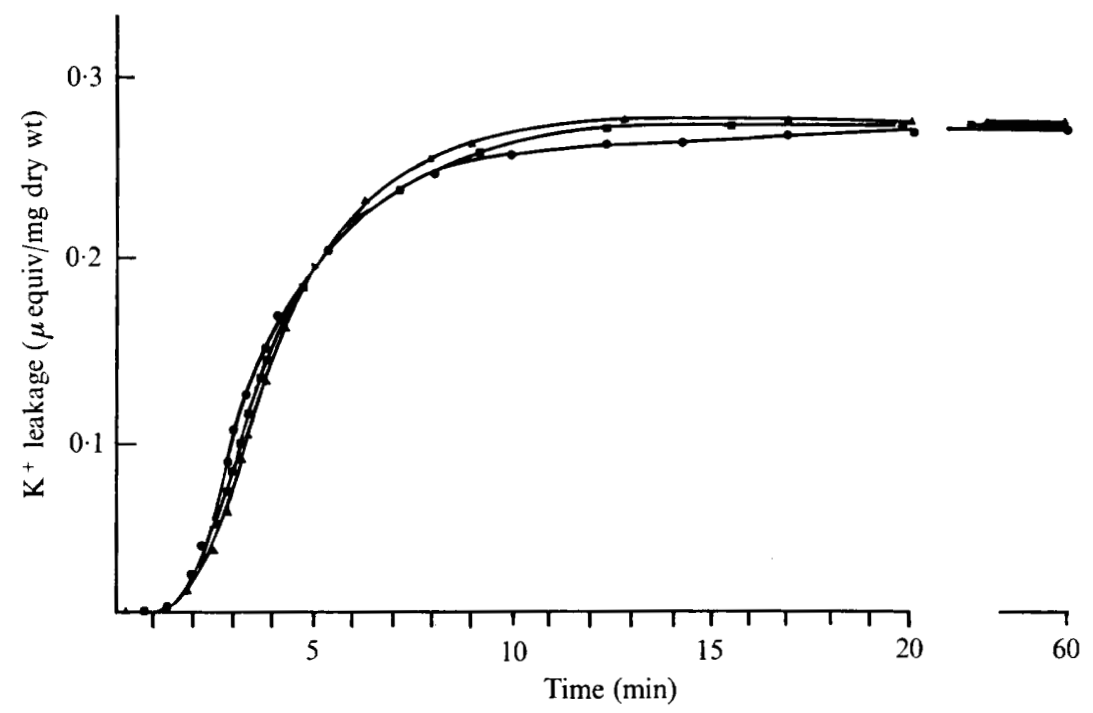

Fig. 4. Potassium leakage from $C$. albicans suspension (exponential phase) caused by $\mathrm{I} 6 \mu \mathrm{M}$-nystatin

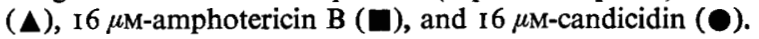

A standardized suspension $(40 \mathrm{ml})$ was placed in a constant temperature vessel at $25^{\circ} \mathrm{C}$, electrodes fitted, $10 \mathrm{ml}$ of the antibiotic solution was added and millivolt readings were taken at $15 \mathrm{~s}$ intervals.

Determination of total free potassium. Suspensions were boiled for $15 \mathrm{~min}$, cooled, and the potassium concentration was determined with the electrode. Alternatively the organisms were first disrupted by either freeze-press methods or ultrasonic sound.

For the freeze press, washed organisms were centrifuged, made into a thick suspension 
Table I. Total non-bound potassium content of Candida albicans by three extraction methods

$\begin{array}{lccc}\text { Disruption } & \text { Exponential phase } & \text { Stationary phase } \\ \text { Method of extraction } & (\%) & 0.38 & 0.40 \\ \text { Heating to } 100^{\circ} \mathrm{C} & - & 0.36 & 0.4 \mathrm{I} \\ \text { Ultrasonic disintegration } & 95 & 0.32 & 0.40\end{array}$

$\left(\mathrm{IO}^{10} / \mathrm{ml}\right)$ and pressed at $-25{ }^{\circ} \mathrm{C}$ under $\mathrm{I} 2$ tonnes following the method of Edebo (I96I). The freeze press (X-press, A. B. Biotech, Croydon) disrupted $92 \%$ of the organisms after 5 passes.

As an alternative, organisms were disrupted with a M.S.E. I00 watt ultrasonic disintegrator, $\mathrm{I} \cdot 8 \mathrm{~cm}$ probe, $20 \mu \mathrm{m}$ amplitude at $20 \mathrm{kHz} / \mathrm{s}$ for $\mathrm{I} 5 \mathrm{~min}$ at $5{ }^{\circ} \mathrm{C}$.

Disrupted preparations were stored at $-20^{\circ} \mathrm{C}$.

\section{RESULTS}

Potassium loss. Fig. I shows the effect of ro $\mu \mathrm{g}$ candicidin $/ \mathrm{ml}$ upon the standardized suspension of Candida albicans. DMSO and distilled water control suspensions give no leakage. Fig. 2 shows the effect of varying the concentration of candicidin. Potassium leaks from organisms treated with concentrations of candicidin which do not slow the rate of C. albicans growth; $20 \mu \mathrm{g} / \mathrm{ml}$ is necessary to produce a non-reversible lethal effect after $2 \mathrm{~h}$ in the standardized suspension (S. M. Hammond, unpublished observations). Very similar leakage patterns are produced by $\mathrm{I} 6 \mu \mathrm{M}$ solutions of amphotericin B, candicidin and nystatin (Figs. 3 and 4 ). The age of culture affected the rate of $\mathrm{K}^{+}$leakage. Organisms grown for $6 \mathrm{~h}$ and known to be in the exponential phase leaked potassium much more rapidly than those grown for $18 \mathrm{~h}$, i.e. in the stationary phase. The stationary phase organisms contain more potassium and consequently slightly more leaks out.

Total non-bound cellular potassium. Table I records values obtained for the total extractable potassium, as determined by three methods. These results demonstrate that organisms from the stationary phase contain more free potassium than those from the exponential phase.

\section{DISCUSSION}

Lampen (1966) proposed that the large ring polyenes amphotericin B, candicidin and nystatin have a common mode of action. Polyenes bind to membrane sterols and this binding affects membrane structure or characteristics in such a way as to damage transport systems for small molecules. It is known that polyenes cause a loss of intracellular potassium from yeasts and other fungi (Drouhet, I968; Kinsky, I967; Venables \& Russell, I972; Zygmunt, 1966).

Detection of potassium leakage after treatment with polyenes has depended on the use of chemical methods or flame photometry. Both methods have the inherent disadvantage that they do not allow a rapidly changing situation to be followed as does the use of a potassiumsensitive electrode.

Potassium-sensitive glass electrodes have been available for many years but these electrodes only retain their selectivity for potassium over hydrogen at a $\mathrm{pH}$ greater than 7 . Ion-specific liquid membrane electrodes, first described by Stefanac \& Simon (1967) who used nonactin 
homologues, do not respond to anions and have the advantage that they can be used at any $\mathrm{pH}$. By using valinomycin as the ion-specific liquid dissolved in diphenyl ether on an inert porous polyvinyl chloride membrane, an electrode was obtained with a high selectivity for $\mathrm{K}^{+}$relative to $\mathrm{Na}^{+}$. Morf, Zust \& Simon (197I) calculated selectivity orders for such membranes and found that valinomycin membranes had high selectivity of $\mathrm{K}^{+}$over $\mathrm{Na}^{+}(4000$ times) and $\mathrm{K}^{+}$over $\mathrm{H}^{+}$(8000 times). The reference double-junction electrode was used to prevent contamination of the reaction vessel by outflowing ions from the reference electrode.

Of the soluble extractable non-bound potassium of Candida albicans, 90 to $95 \%$ was released by polyene treatment within I $5 \mathrm{~min}$, showing the necessity (and advantage) of using an electrode to measure the time course.

After addition of antibiotic, no leakage occurs for approximately $90 \mathrm{~s}$ in the case of organisms from the exponential phase of growth and for approximately $3 \mathrm{~min}$ for those from the stationary phase. This may be the time taken for the antibiotic to penetrate the cell wall and attach to the membrane sterol. Lampen, Arnow, Borowska \& Laskin (1962) stated that there was a time-dependent binding of nystatin to membranes of yeast and that this time dependence was related to the physiological state of the organism. He stated that these differences were related to the differing permeabilities of young organisms as compared to older stationary phase ones, the latter binding polyenes more slowly than the former.

Equimolar solutions of candicidin, nystatin and amphotericin B produced almost identical leakage patterns, confirming the suggestion of Lampen et al. (1962) that these three polyenes have a common site of action and that equimolar solutions cause the same number of damaged sites in the membrane and consequently the same amount of potassium efflux.

Cass, Finkelstein \& Krepsi (1970) demonstrated that on thin artificial membranes, amphotericin B and nystatin produce pores that they believed to be anion selective, while candicidin produces pores believed to be cation selective. They suggested that the pores opened and closed continuously, this mechanism being determined by single salt diffusion potentials; they also stated that the mechanism of anionic or cationic selectivity was obscure. No evidence of this selectivity could be seen in our experiments, the three polyenes behaving almost identically with respect to potassium efflux.

\section{REFERENCES}

Cass, A., Finkelstern, A. \& Krepsi, V. (1970). The ion permeability induced in thin lipid membranes by the polyene antibiotics nystatin and amphotericin B. Journal of General Physiology 56, 100-124.

Edebo, L. (1961). Disintegration by freeze pressing. II. Effect on fungi. Acta pathologica et microbiologica scandinavica 52, 36I-8.

Drouhet, E. (1968). Some biological activities of antifungal antibiotics and their mode of action. In Ciba Foundation Symposium on Systemic Mycoses. Edited by G. Wolshenholme and R. Porter. London: Churchill.

KInSKy, S. C. (1967). Polyene antibiotics. In Antibiotics, Vol. r. Mechanism of Action. Edited by D. Gottleib and P. Shaw. Berlin: Springer Verlag.

LAMPen, J. O. (1966). Polyene antibiotics and membrane function. Symposia of the Society for General Microbiology 16, I I I-130.

Lampen, J. O., Arnow, P., Borowska, Z. \& Laskin, A. (1962). Location and role of sterols in nystatinbinding sites. Journal of Bacteriology 84, I I 52-60.

MORF, W. E., ZuST, U. \& Simon, W. (I97I). Alkali cation specificity of antibiotics, their behaviour in bulk membranes and in ion selective sensors. In Proceedings of Symposia on Molecular Mechanisms of Antibiotic Action on Protein Biosynthesis and Membranes. University of Granada, pp. 523-544. Amsterdam: Elsevier.

Simpson, J. (1963). Microbiological assay using large plate methods. In Analytical Microbiology. Edited by F. Kavanagh. New York: Academic Press. 
StEFANAC, Z. \& Simon, W. (1967). The ion specific electrochemical behaviour of macrotetralides in membranes. Microchemical Journal 20, 125-132.

Venables, P. \& Russell, A. (1972). Some effects of nystatin on Saccharomyces cerevisiae. Microbios 6, 239-246.

ZYGMUNT, W. (1966). Intracellular loss of potassium in C. albicans, after exposure to polyene antifungal antibiotics. Applied Microbiology 14, 953-956. 